\title{
Water sorption and water permeability properties of edible film made from potato peel waste
}

\author{
Siti Hajar OTHMAN ${ }^{1,2 *}$, Siti Amirah Mohammad EDWAL ${ }^{1}$, Nazratul Putri RISYON ${ }^{1}$, \\ Roseliza Kadir BASHA ${ }^{1}$, Rosnita A. TALIB ${ }^{1}$
}

\begin{abstract}
The water sorption and permeability properties of edible film produced from potato peel waste was investigated under different levels of relative humidity $(23,33,43,57,75 \% \mathrm{RH})$ and temperatures $\left(5,30,50^{\circ} \mathrm{C}\right)$. The water sorption behaviour and isotherms of the film were investigated by fitting water sorption data to the Peleg model and the Guggenheim, Anderson de Boer model (GAB model). The amount of moisture content, time required for the moisture content of the film to reach equilibrium, water sorption rate, and water sorption capacity increased when the relative humidity increased. The effect of temperature on moisture content, water sorption rate, water sorption capacity, and monolayer moisture content is complex and related to the water activity as well as the moisture content. Based on $\mathrm{R}^{2}$ and RMSE values, the Peleg and GAB models were respectively determined as excellent models to predict the water sorption properties of the films, thus supporting the reliability of water sorption behaviour prediction. The water vapour transmission rate and water vapour permeability increased with an increase in relative humidity and temperature. The sorption and permeability properties of the film are worth investigation since the final application of the film as food packaging is ultimately dependent on these behaviours.
\end{abstract}

Keywords: edible film; food packaging; water permeability; water sorption.

Practical Application: Edible film, food packaging material.

\section{Introduction}

Most of the materials used for food packaging applications are non-biodegradable such as plastic made from petroleum. Thus these products do not meet the growing demand in society for sustainability and they are not safe for the environment (Othman, 2014). To overcome this problem there is a need to find alternative food packaging materials and among these, edible film appears to be the most favourable alternative. This is because edible film is environmentally friendly whereby the film can be consumed together with the products packaged within it and thus there is no food packaging to be disposed of (Shit \& Shah, 2014). Further, edible film could reduce pollution in the environment because the films are usually created especially from ingredients that are edible and renewable, thus are able to disintegrate more readily than other packaging material (Bourtoom, 2008). Other than being environmental friendly (Das \& Chowdhury, 2016), edible film has the ability to lengthen the shelf life of foodstuffs packaged with it and to protect the foodstuffs from environmental effects such as moisture loss and the browning effect (Robertson, 2012).

Edible film is defined as a consumable thin layer that is positioned as barrier between any food and the surrounding environment (Skurtys et al., 2010). It can be produced from potato peel which contains starch due to the naturally present biopolymers which are predominantly polysaccharides (Bergo et al., 2008) such as pectin, starch, and cellulose derivatives. Such an application of potato peel provides benefit in combining the barrier and mechanical properties of polysaccharides besides the nutritious properties of the potato peel itself (Azeredo et al., 2012). Moreover, production of edible film is also noteworthy to minimise potato peel waste from the food industry for example in the manufacture of potato chips and fried potatoes.

However, polysaccharide films exhibit a weak water vapour barrier owing to their hydrophilic characteristic (Skurtys et al., 2010; Slavutsky \& Bertuzzi, 2016) whereby they tend to absorb moisture from the surroundings. Although many studies have been undertaken to determine the many properties of films that are edible (Britto \& Assis, 2010; Weng et al., 2014), the studies regarding the barrier properties of the films has been limited to date. As a promising food packaging material, knowledge of the barrier properties that include water sorption and water permeability of the film is much needed because the final application of the films will ultimately depends on these factors. To function as a food packaging material, reliable sorption data of the edible film is needed for the prediction of the food quality of the packaged items. Moisture content plays a prominent role in determining the performance of edible film as a food packaging material because moisture is a transferable element which can pass through the film either by adsorption or desorption and may change the properties of the film and the packaged food product (Bourlieu et al., 2009). Thus, the shelf life of the edible 
film as well as the food wrapped within the film is dependent on the transferability of the moisture between the film and its surroundings. Several factors influence the amount and rate of moisture that can transfer or diffuse, including the surrounding humidity and temperature. These factors need to be controlled to ensure the efficiency of the edible film as well as the integrity of the food product.

The objective of this study is to investigate the effect of two imperative factors, namely, the relative humidity $(23,33,43,57,75 \% \mathrm{RH})$ and temperature $\left(5,30,50^{\circ} \mathrm{C}\right)$ on the water sorption and water permeability properties of edible film made from potato peel waste. Water sorption data was fitted to the Peleg model and the Guggenheim, Anderson de Boer model (GAB model) to determine the water sorption rate, water sorption capacity, and sorption isotherms. The water vapour transmission rate and water vapour permeability were determined using the cup method.

\section{Materials and methods}

\subsection{Preparation of films}

The potato peel waste was obtained from a food stall that sells fried potato flesh in Serdang, Selangor, Malaysia. The potato peel was first washed using tap water to eliminate any dirt on the potato skin and was oven dried at $45^{\circ} \mathrm{C}$ for 72 hours (Farvin et al., 2012). The dried potato peel was then ground into powder and was sieved using a $64 \mu \mathrm{m}$ mesh sieve to obtain a fine powder to be used in the film preparation. The powder retained in the mesh was reground again.

An amount of $5 \mathrm{~g}$ of potato peel powder was mixed with $100 \mathrm{ml}$ of distilled water followed by the addition of $2 \mathrm{ml}$ of plasticiser, specifically glycerol (R\&M Chemical), and $1 \mathrm{~g}$ of anti-browning agent, specifically ascorbic acid (R\&M Chemical). The solution mixture was then transferred to a water bath shaker where the temperature of the mixture solution was maintained at $90{ }^{\circ} \mathrm{C}$ and shaken at $60 \mathrm{rpm}$ speed for 30 minutes. Then, the mixture solution was cooled at room temperature. The cooled mixture solution was poured into an aluminium casting tray $\left(484 \mathrm{~cm}^{2}\right)$ and covered with transparent film at the bottom of the casting tray. The purpose of the transparent film was to simplify the peel-off process of the dried film. Then, the casting tray was placed into a natural convection oven at $50{ }^{\circ} \mathrm{C}$ for 26 hours to dry the sample film. Finally, the edible film form was peeled off from the transparent film. The thickness of the film was measured using a hand micrometre and the average thickness of the film was found to be $0.10 \pm 0.01 \mathrm{~mm}$.

\subsection{Moisture curve and rates}

The edible film made from potato peel waste was cut into squares with dimensions $30 \mathrm{~mm} \times 30 \mathrm{~mm}$ and placed inside a desiccator containing silica gel ( $0 \%$ relative humidity) for five days at a constant temperature of $30^{\circ} \mathrm{C}$ (Suppakul, 2006). The desiccator was located inside an incubator (Incucell, MMM, Germany) to ensure a constant temperature of $30^{\circ} \mathrm{C}$. The desiccator acted as a humidity controller for film storage in the water sorption analysis including during film preparation. A relative humidity meter (NT-312, ProsKit, USA) was used to ensure that the relative humidity inside the desiccator was constant. The weight of the film before it was placed inside the desiccator was measured and labelled as $W_{i}$. Then, the weight of the film after it was pre-dried inside the desiccator for five days was measured and labelled as $W_{d}$. The initial moisture content was determined as follows (Equation 1):

$M_{i}=\left(W_{i}-W_{d}\right) / W_{d}$

where $M_{i}$ is the initial moisture content (\% dry basis), $W_{i}$ is the initial weight of the sample $(\mathrm{g}), W_{d}$ is the dry weight of the sample after being pre-dried in the desiccator $(\mathrm{g})$.

The five-day pre-dried films were then placed inside separate desiccators with different saturated salt solutions in triplicate samples for each salt solution. The saturated salt solutions used in this experiment were Potassium Acetate, Magnesium Chloride, Potassium Carbonate, Sodium Bromide, and Sodium Chloride with a relative humidity of $23,33,43,57$, and $75 \%$ respectively. The water sorption properties of the potato films were studied at three different temperatures; $5{ }^{\circ} \mathrm{C}, 30^{\circ} \mathrm{C}$ and $50^{\circ} \mathrm{C}$. Therefore, the desiccators were placed separately in conditioning equipment such as a chiller (Remi, India) set at $5{ }^{\circ} \mathrm{C}$ and an incubator set at $30^{\circ} \mathrm{C}$ and $50{ }^{\circ} \mathrm{C}$ respectively. Thermometers (Economy Thermometer (Mercury), Promolab, France) were placed inside the equipment to confirm the surrounding temperature (equipment environment). Figure 1 shows a schematic diagram of the equipment used for the water sorption study. The weight gained for each sample was determined using a digital balance for the first 2 and 5 hours. After that, the weight of the film was measured periodically every 24 hours for seven days.

The moisture sorption data of the film was fitted to a mathematical model, specifically the Peleg model. The Peleg model has been widely utilised to describe the sorption process in various foods, especially starchy and oily food types (Turhan et al., 2002). The following is the equation (Equation 2) proposed by Peleg (1998):

Table 1. Water sorption rate $\left(k_{1}\right)$, water sorption capacity $\left(k_{2}\right)$, and regression square $\left(\mathrm{R}^{2}\right)$ obtained from water sorption data fitted to Peleg model.

\begin{tabular}{|c|c|c|c|c|c|c|c|c|c|}
\hline \multirow{2}{*}{$\begin{array}{l}\text { Relative } \\
\text { humidity }\end{array}$} & \multicolumn{3}{|c|}{ Temperature $=5^{\circ} \mathrm{C}$} & \multicolumn{3}{|c|}{ Temperature $=30^{\circ} \mathrm{C}$} & \multicolumn{3}{|c|}{ Temperature $=50^{\circ} \mathrm{C}$} \\
\hline & $k_{1}$ & $k_{2}$ & $\mathbf{R}^{2}$ & $k_{1}$ & $k_{2}$ & $\mathbf{R}^{2}$ & $k_{1}$ & $k_{2}$ & $\mathbf{R}^{2}$ \\
\hline $23 \%$ & 0.558 & 0.180 & 0.993 & 0.197 & 0.199 & 0.995 & 0.136 & 0.075 & 0.994 \\
\hline $33 \%$ & 0.388 & 0.113 & 0.996 & 0.154 & 0.140 & 0.999 & 0.136 & 0.076 & 0.998 \\
\hline $43 \%$ & 0.150 & 0.079 & 0.998 & 0.102 & 0.080 & 0.999 & 0.102 & 0.053 & 0.990 \\
\hline $57 \%$ & 0.132 & 0.041 & 0.992 & 0.084 & 0.064 & 0.998 & 0.091 & 0.044 & 0.989 \\
\hline $75 \%$ & 0.121 & 0.024 & 0.994 & 0.015 & 0.028 & 0.999 & 0.036 & 0.024 & 0.998 \\
\hline
\end{tabular}


$M(t)=M_{i}+t /\left(k_{1}+k_{2} t\right)$

where $M(t)$ is the moisture at time $\mathrm{t}(\%), M_{i}$ is the initial moisture (\%), $k_{1}$ is the Peleg rate constant, and $k_{2}$ is the Peleg capacity constant. By rearranging Equation 2:

$t /\left(M_{t}-M_{i}\right)=k_{1}-k_{2} t$

A curve of $t /\left(M_{t}-M_{i}\right)$ versus time was plotted to produce a straight line with $k_{1}$ (the water sorption rate) as intercept and $k_{2}$ (water sorption capacity) as the gradient of the graph.

\subsection{Water sorption isotherm}

The water sorption isotherm was determined by fitting the data using the GAB model. This model was chosen because it has been widely employed in the determination of the sorption behaviour of food products (Mali et al., 2005). The data was fitted using the following equation (Equation 4):

$\frac{M_{e}}{W_{m}}=\frac{C k a_{w}}{\left(1-k a_{w}\right)\left(1-k a_{w}+C k a_{w}\right)}$

where, $M_{e}$ is the equilibrium moisture content of the sample on a dry basis $(\mathrm{mg}), W_{m}$ is the GAB monolayer moisture content, $C$ is the Guggenheim constant, $a_{w}$ is the water activity (\%) and $k$ is a factor correcting the properties of the multiplayer molecules corresponding to the bulk liquid.

The equilibrium moisture content was obtained when the difference of the weight between two successive sample measurements was not greater that 1\% (Mali et al., 2005). The equilibrium moisture content was obtained using the following equation (Equation 5):

$M_{e}=\frac{W_{e}}{W_{i}}\left(M_{i}+1\right)-1$

where $M_{e}$ is the equilibrium moisture content (mg dry basis), $W_{i}$ is the initial weight of the sample (mg), $M_{i}$ is the initial moisture content of the product (\% dry basis), and $W_{e}$ is the equilibrium weight of the sample (mg).

The three parameters for the GAB model, $W_{m}, C$, and $k$ were determined from the second order polynomial form of $y=\alpha_{w} / M_{e}=\alpha_{w}{ }^{2}+\beta \alpha_{w}+\gamma$ where,

$\alpha=\frac{k}{W_{m}[1 / C-1]}$

$\beta=\frac{1}{W_{m}[1-2 / C]}$

$\gamma=\frac{1}{W_{m} k C}$

This model was solved using the linear regression analysis method to obtain $\alpha, \beta$, and $\gamma$ and subsequently the parameter values $W_{m}, C$ and $k$ were obtained from the substitution calculation method using Equations 6-8.
The root mean square error (RMSE) was measured to determine the differences between the equilibrium moisture content determined from the experimental data $\left(M_{\text {eexp }}\right)$ and the equilibrium moisture content predicted using the GAB model $\left(M_{\text {ecalc }}\right)$. An RMSE value of $10 \%$ and less indicates an excellent fit using the model (Jamieson et al., 1991). The following is the equation (Equation 9) used to calculate the RMSE value (Mok \& Hettiarachchy, 1990):

$R M S E=\sqrt{\frac{\sum\left[\left(M_{\exp }-M_{c a l c}\right) / M_{\exp }\right]^{2}}{N}} \times 100$

\subsection{Water vapour permeability}

The water vapour permeability of the film was studied using the JIS Z 0208 method. A circular test cup (No. 318 Water Permeability Cup) was used to determine the water vapour permeability of the film. The film was first cut into a circular shape that was larger than the inner diameter of the cup. Then, the cup was placed on a horizontal platform. Anhydrous Calcium Chloride as a desiccant with $0 \%$ relative humidity was placed inside the cup. Subsequently, the edible film made from potato peel waste was placed on top of the permeability cup (Talja et al., 2007). The cup was then covered and sealed with liquid paraffin. After the liquid paraffin solidified, the cup was weighed in order to calculate the initial weight. The cup was then located inside a desiccator that contained a saturated salt solution. Three types of salt solution (Magnesium Chloride, Sodium Bromide and Sodium Chloride) at different levels of relative humidity $(33,57$, and $75 \%)$ were used. The water permeability properties of the potato films were also studied at three different temperatures at $5^{\circ} \mathrm{C}, 30^{\circ} \mathrm{C}$ and $50{ }^{\circ} \mathrm{C}$. To achieve this the desiccators were placed separately in conditioning equipment such as a chiller set at $5{ }^{\circ} \mathrm{C}$ and incubators set at $30^{\circ} \mathrm{C}$ and $50{ }^{\circ} \mathrm{C}$ respectively. Thermometers were placed inside the equipment to confirm the surrounding temperature (equipment environment). The weight of the cup was recorded every 24 hours until the difference in mass was not more than $10 \%$. The water vapour permeability (WVP) and water vapour transmission rate (WVTR) were determined using the following equations (Equations 10, 11):

$W V T R=(\Delta m / \Delta t A)$

$W V P=W V T R(L / \Delta p)$

where $\Delta m / \Delta t$ is the moisture gain weight per time $(\mathrm{g} / \mathrm{s}), A$ is the exposed surface area of the film $\left(\mathrm{m}^{2}\right), L$ is the thickness of the film (mm), and $\Delta p$ is the difference of partial pressure (Jouki et al., 2013).

\section{Results and discussion}

\subsection{Moisture curve}

Edible film made from potato peel waste was first pre-dried for five days to remove the initial moisture inside the film. After five days, the film lost an average of $7.30 \%$ moisture content which was designated as the initial moisture content of the film $\left(M_{i}\right)$. Figure $2 \mathrm{a}-\mathrm{c}$ shows the water sorption data of the film over a period of seven days (168 hours) for different levels of relative 
humidity and temperatures. The moisture content of the film increased rapidly for the first 7 hours which indicates the early stage of water sorption of the film. After around 24 hours, the moisture content of the edible film attained a plateau, implying that the moisture content equilibrated with the relative humidity (Mali et al., 2005). Upon reaching equilibrium, the amount of water being adsorbed increases as the relative humidity increases. For example, it can be clearly seen from Figure $2 \mathrm{a}$ that at a temperature of $5^{\circ} \mathrm{C}$, the amount of moisture content of the film when stored at $75 \%$ relative humidity $(\mathrm{RH})$ was much greater than the film stored at $23 \% \mathrm{RH}$. The time required to reach equilibrium also increased when the relative humidity increased. At $5{ }^{\circ} \mathrm{C}$, the time required for the film stored at $23 \%$ $\mathrm{RH}$ to equilibrate with the surroundings was around 24 hours compared to around 96 hours when stored at 75\% RH.

These findings suggest that relative humidity is an imperative parameter that could affect both the amount of moisture content and the time needed for the moisture content of the film to

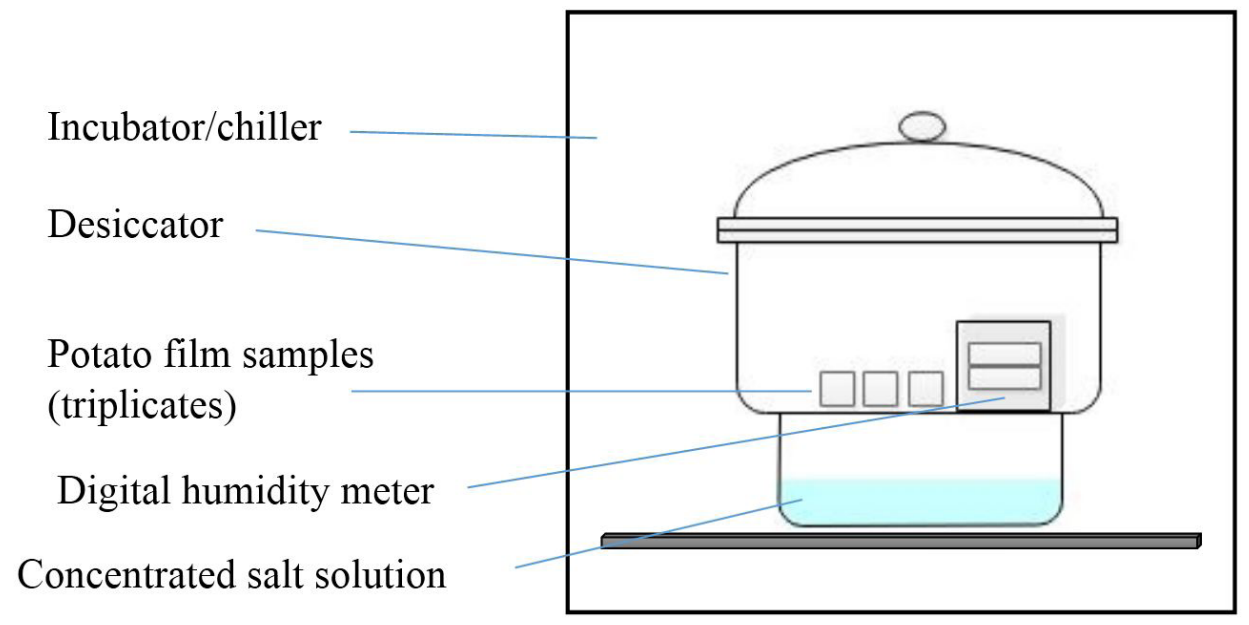

Figure 1. Schematic diagram of equipment used for water sorption study.
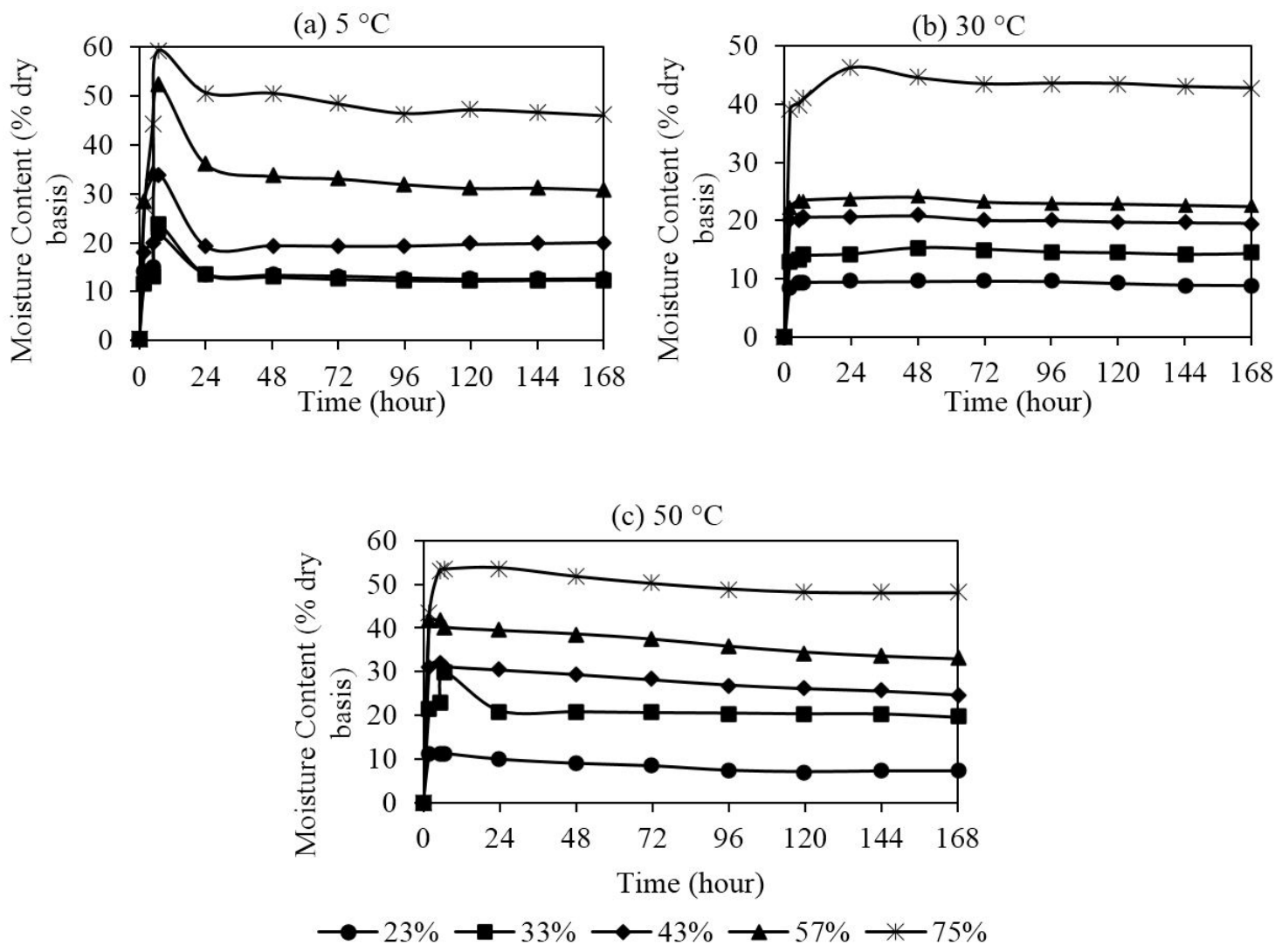

Figure 2. Water sorption data of edible film made from potato peel waste at different levels of relative humidity $(23,33,43,57,75 \% \mathrm{RH})$ and temperatures of (a) $5{ }^{\circ} \mathrm{C}$; (b) $30^{\circ} \mathrm{C}$; and (c) $50^{\circ} \mathrm{C}$. 
achieve equilibrium with the surroundings. The reason for this finding is due to the fact that when the surroundings have a high relative humidity the air contains a large amount of water molecules that can be adsorbed by the film, thus there will be a high amount of moisture content inside the film when there is high relative humidity. Increasing the moisture content at a high relative humidity will cause the film to swell, opening up new binding sites for water, hence increasing the equilibrium moisture content (Chowdhury \& Das, 2012). Mostafa \& Sourell (2009) reported that the increase of equilibrium moisture content is also attributable to a decrease in the vapour pressure insufficiency at high relative humidity. This produces an atmosphere near to saturation, thus increasing the capability of the film to absorb extra moisture from the atmosphere. Furthermore, at high relative humidity, there is a big difference of water activity between the film and the surroundings, thus, it takes more time for the water sorption activity to achieve equilibrium. Hence, the time required for the moisture content to achieve equilibrium increases with increasing relative humidity.

Figure 2 also demonstrates the effect of temperature on the water sorption. Figure $2 \mathrm{a}-\mathrm{b}$ shows that upon reaching equilibrium, at constant relative humidity, the moisture content decreases when the temperature increases whereby the equilibrium moisture content at $30^{\circ} \mathrm{C}$ was lower compared to the figure at a temperature of $5^{\circ} \mathrm{C}$. This finding appears to be consistent with the findings of Chowdhury \& Das (2012), who attributed an increase in temperature caused in an increase in water activity of the film, thus reducing the total number of water binding sites because the temperature induced a modification in the structure of the film. An increase in temperature will result in a high energy level that causes the water molecules to become unstable, active, and escape from the binding sites, which decreases the moisture content of the film (Mostafa \& Sourell, 2009). According to Alakali \& Satimehin (2009), from a thermodynamic point of view, an increase in temperature leads to a decrease in the quantity of water adsorbed, thus lowering the equilibrium moisture content.

However, the findings from Figure 2b-c appear to contradict this finding. At a constant relative humidity, the moisture content at a temperature of $50{ }^{\circ} \mathrm{C}$ is higher compared to the moisture content at a temperature of $30^{\circ} \mathrm{C}$. This opposite behaviour has also been observed by Chowdhury \& Das (2012). According to those authors, at any specific moisture content a temperature increase results in a reduction in water activity of the film, implying additional new binding sites for water to open, and therefore decreasing the free energy as well as the water activity of the bound water. Thus, an increase in temperature will result in an increase in the moisture content rather than a decrease in moisture content. In other words, if the temperature is high, then the surrounding air has a greater capacity to hold more water in a vapour state than at lower temperatures, thus resulting in an increase in moisture content. Few studies have reported an increase in water binding at a high temperature for food rich in soluble solids and prone to structural orientation (Das \& Das, 2002; Rizvi, 1986). It can be deduced that the relationship between moisture content and temperature is complex and related to the water activity as well as moisture content.

\subsection{Water sorption analysis using Peleg model}

The water sorption data of the film over a period of seven days (168 hours) at different levels of relative humidity and temperature was then fitted using the Peleg model (Equation 3). The $k_{1}$, water sorption rate and the $k_{2}$, water sorption capacity as well as the $\mathrm{R}^{2}$, regression value were determined from the fitted curve and tabulated in Table 1 . It can be clearly observed from the table that the $\mathrm{R}^{2}$ values are around 0.99 which indicates the strong reliability of the Peleg model in describing the water sorption behaviour of the edible films.

In general $k_{1}$ and $k_{2}$ decreased with an increase in relative humidity. The lower the value of $k_{1}$, the higher the initial water sorption rate (Peleg, 1998). The lower the value of $k_{2}$, the higher the sorption capacity of the edible film (Mali et al., 2005). This result indicates that the water sorption rate and water sorption capacity increased with an increase in relative humidity which means that the film adsorbed faster and stored more water when kept in high relative humidity surroundings (Mali et al., 2005). This was due to the high concentration of water molecules in the air resulting in high kinetic energy that enhanced the sorption of the water into the film. This finding appears to be supported by the previous discussion (Section 3.1) whereby the increase in relative humidity resulted in an increase in equilibrium moisture content.

In terms of temperature, for the various levels of relative humidity in the range of $23 \%$ to $33 \%, k_{1}$ decreased when the temperature increased from $5{ }^{\circ} \mathrm{C}$ to $50{ }^{\circ} \mathrm{C}$. This finding is consistent with the work of Turhan et al. (2002) in which the water sorption increased with an increase in temperature and resulted in a lower $k_{1}$ value. This was due to the water-starch reaction that related to the gelatinisation temperature of the edible film which lowered the activation energy for the rate of water to be transferred (Turhan et al., 2002). For the various levels of relative humidity in the range $43 \%$ to $75 \%, k_{1}$ decreased and then increased with the increase in temperature from $5{ }^{\circ} \mathrm{C}$ to $30^{\circ} \mathrm{C}$ and from $30^{\circ} \mathrm{C}$ to $50^{\circ} \mathrm{C}$ respectively, suggesting that the water sorption rate increased from $5{ }^{\circ} \mathrm{C}$ to $30^{\circ} \mathrm{C}$ and then decreased from $30^{\circ} \mathrm{C}$ to $50^{\circ} \mathrm{C}$. It can be speculated that at any particular relative humidity, a temperature increase results in an increase in the water sorption rate, most probably due to additional new binding sites opening for water to be adsorbed. Similarly, an increase in temperature at any particular relative humidity can also result in a decrease of water sorption perhaps due to a high energy level causing the water molecules to become unstable and escape from the binding sites, thus decreasing the water sorption rate.

In general there is a trend of $k_{2}$ increasing and then decreasing when the temperature increases from $5^{\circ} \mathrm{C}$ to $30^{\circ} \mathrm{C}$ and from $30^{\circ} \mathrm{C}$ to $50^{\circ} \mathrm{C}$ respectively, suggesting that the water sorption capacity decreased from $5^{\circ} \mathrm{C}$ to $30^{\circ} \mathrm{C}$ and then increased from $30^{\circ} \mathrm{C}$ to $50^{\circ} \mathrm{C}$ which contradicts the findings for the $k_{1}$ values. Thus, it can be deduced that for edible film made from potato peel, the effects of temperature reveal that the relationship for the water sorption capacity is reciprocal to the water sorption rate. A slow water sorption rate offers a higher chance for the film to hold more water, hence the high water sorption capacity. This is probably due to the slow water sorption process, resulting 
in less water lost to the surroundings. These findings appear to be consistent with the previous results (Section 3.1) in which the equilibrium moisture content decreased as the temperature increased from $5{ }^{\circ} \mathrm{C}$ to $30^{\circ} \mathrm{C}$, perhaps due to a decrease in the $k_{1}$ value and an increase in the $k_{2}$ value (an increase in the water sorption rate and a decrease in the water sorption capacity) and a temperature increase from $30{ }^{\circ} \mathrm{C}$ to $50{ }^{\circ} \mathrm{C}$ perhaps due to an increase in the $k_{1}$ value and a decrease in the $k_{2}$ value (a decrease in water sorption rate and an increase in water sorption capacity). These findings are noteworthy to be determined since the sorption behaviour of any film needs to be studied thoroughly before it can be used for the designated application, particularly for a food packaging application.

\subsection{Water sorption isotherms using the GAB model}

To investigate the water sorption isotherms of the film, the water sorption data of the films at different levels of relative humidity and temperature was then fitted using the GAB model (Equation 4, aw $/ \mathrm{M}_{\mathrm{e}}$ versus aw). The fitted curves resulted in a second order polynomial equation and the constant values obtained from the equation were used to determine the GAB constant parameters or moisture sorption isotherms which include the factor correcting properties of a multilayer molecule $(\mathrm{k})$, $\mathrm{GAB}$ monolayer moisture content $\left(\mathrm{W}_{\mathrm{m}}\right)$, and the Guggenheim constant (C) (Equations 6-8). These values including the $\mathrm{R}^{2}$ and RMSE values are tabulated in Table 2.

According to Chukwu (2010), the monolayer moisture content corresponds to the minimum moisture to avoid auto-oxidation and to improve the stability of the product throughout the storage period and it is dependent of the technique used to equilibrate the moisture. However, at the level of the monolayer moisture content, there is still the possibility for some trace elements to be exposed, which results in a browning effect. Table 2 shows that the monolayer moisture content increased from $0.065 \mathrm{~g}$ to $0.090 \mathrm{~g}$ water per $\mathrm{g}$ solid with the increase in temperature from $5{ }^{\circ} \mathrm{C}$ to $30{ }^{\circ} \mathrm{C}$. This was probably due to the high temperature that has the ability to decrease the moisture content in the surroundings. Hence a higher amount of moisture was required to cause auto-oxidation as well as to impair the stability of the edible film throughout the storage period.

On the other hand, the monolayer moisture content decreased from $0.090 \mathrm{~g}$ to $0.030 \mathrm{~g}$ water per $\mathrm{g}$ solid as the temperature further increased from $30^{\circ} \mathrm{C}$ to $50{ }^{\circ} \mathrm{C}$. According to Akoy et al. (2013), the decrease in the monolayer moisture content of the edible film at higher temperatures is expected since the total number of active sorption sites for water binding decreases owing to physical or chemical changes in the film that are caused by the temperature rise. Strauss et al. (1991) stated that the monolayer moisture content value is the maximum volume of water in a single layer per gram of dry film that could be adsorbed. The monolayer moisture content value also indicates the number of sorption sites. The higher the temperature, the lower the monolayer moisture content and the lower the number of sorption sites. Hence, in high temperature and high relative humidity storage, the lower are the chances to prevent auto-oxidation and the higher the chances of the edible film becoming unstable during storage.

Moreover, in comparison with the water sorption rate findings discussed previously (Section 3.2), it is obvious that the trend of the monolayer moisture is linear to the trend of the water sorption rate whereby both the monolayer moisture content and the water sorption rate increase with a temperature increase from $5{ }^{\circ} \mathrm{C}$ to $30^{\circ} \mathrm{C}$ and decreased from $30^{\circ} \mathrm{C}$ to $50{ }^{\circ} \mathrm{C}$. This is consistent with the definition of monolayer moisture content which is the maximum volume of water which can be adsorbed by a single layer per gram of dry film (Strauss et al., 1991). Hence, the higher the water sorption rate, the higher the monolayer moisture content.

From Table 2, the RMSE values for temperatures of 5, 30, and $50{ }^{\circ} \mathrm{C}$ respectively were $1.06,0.60$, and $4.23 \%$. These values, all of which are less than $10 \%$, indicate excellent fitting of the data using the GAB model (Jamieson et al., 1991). This demonstrates that the model used is reliable and good at predicting the moisture sorption behaviour of the edible film.

\subsection{Water vapour permeability}

The water vapour transmission rate (WVTR) is the rate of water vapour permeating through the film. In this work, the WVTR is determined from the slope of the regression line of sample weight versus time graph whereby the slope is then divided by the area of the film being exposed to the transmission (Equation 10). Table 3 tabulates the WVTR values as well as water vapour permeability values calculated from the WVTR values (Equation 11).

Table 3 shows that the WVTR increased with an increase in the level of relative humidity. For example, the WVTR for the sample stored at $5^{\circ} \mathrm{C}$ increased from 14.04 to $133.51 \mathrm{~g} /$ day $\cdot \mathrm{m}^{2}$ as the relative humidity increased from 33 to $75 \%$. This is due to the availability of a high concentration of water molecules in the surroundings, thus increasing the WVTR of the edible film. This finding appears to be consistent with the previous findings which stated that as the WVTR increased with relative humidity, the water sorption rate, water sorption capacity, and equilibrium moisture content also increased with relative humidity.

Table 2. GAB constant parameters for edible film at different temperatures.

\begin{tabular}{cccr}
\hline Constant & Temperature $=\mathbf{5}^{\circ} \mathbf{C}$ & Temperature $=\mathbf{3 0}{ }^{\circ} \mathbf{C}$ & Temperature $=\mathbf{5 0}{ }^{\circ} \mathbf{C}$ \\
\hline $\mathbf{k}$ & 1.083 & 0.977 & 1.169 \\
$\mathbf{W}_{\mathbf{m}}$ & 0.065 & 0.090 & 0.030 \\
$\mathbf{C}$ & 10.618 & 6.316 & -5.747 \\
$\mathbf{R}^{2}$ & 0.996 & 0.997 & 0.963 \\
$\mathbf{R M S E}(\%)$ & 1.06 & 0.60 & 4.23 \\
\hline
\end{tabular}


Table 3. The slope of the linear regression line of the sample weight vs time graph, the WVTR, and water vapour permeability of the film for different levels of relative humidity and temperature.

\begin{tabular}{|c|c|c|c|c|c|c|c|c|c|}
\hline \multirow{2}{*}{$\begin{array}{l}\text { Relative } \\
\text { Humidity }\end{array}$} & \multicolumn{3}{|c|}{$\begin{array}{l}\text { Slope, } \Delta W / \Delta t \\
\quad(g / \text { day })\end{array}$} & \multicolumn{3}{|c|}{$\begin{array}{c}\text { WVTR } \\
\left((\mathrm{g} / \text { day }) / \mathbf{m}^{2}\right)\end{array}$} & \multicolumn{3}{|c|}{$\begin{array}{l}\text { Water Vapour Permeability } \\
\left(\text { g.mm } /\left(\mathbf{m}^{2} . \text { day.mmHg }\right)\right)\end{array}$} \\
\hline & $5^{\circ} \mathrm{C}$ & $30^{\circ} \mathrm{C}$ & $50^{\circ} \mathrm{C}$ & $5^{\circ} \mathrm{C}$ & $30^{\circ} \mathrm{C}$ & $50^{\circ} \mathrm{C}$ & $5^{\circ} \mathrm{C}$ & $30^{\circ} \mathrm{C}$ & $50^{\circ} \mathrm{C}$ \\
\hline $33 \%$ & 0.040 & 0.230 & 0.213 & 14.04 & 81.49 & 75.26 & 0.046 & 0.268 & 0.247 \\
\hline $75 \%$ & 0.378 & 0.465 & 0.496 & 133.51 & 164.57 & 175.53 & 0.193 & 0.238 & 0.254 \\
\hline
\end{tabular}

In general, the WVTR also increased with an increase in temperature. For example, the WVTR for the sample stored at $75 \% \mathrm{RH}$ increased from 133.51 to $175.53 \mathrm{~g} /$ day $\cdot \mathrm{m}^{2}$ as the temperature increased from $5{ }^{\circ} \mathrm{C}$ to $50^{\circ} \mathrm{C}$. Cuq et al. (1997) in their study stated that an increase in temperature involves an increase in the water vapour transmission rates. This is due to the high energy held in the storage area of the film which increases the activeness of the water molecules, thus easing the transmission of the water vapour through the film.

Since the water vapour permeability is directly proportional to the WVTR values (Equation 11), it is expected for the water vapour permeability values to exhibit the same trend as that of the WVTR. In general, the water vapour permeability through the film increases with an increase in the relative humidity and temperature. According to Bajpai et al. (2011), the water vapour permeability is proportionally constant and is assumed to be independent of the water vapour gradient across the film. Nonetheless, polysaccharides and protein films that contain hydrophilic polar groups will interact with the water molecules, triggering deviancy in the permeability constant. As the humidity increases, the WVTR also increases due to the variation in vapour pressure across the film that results in permeation, thus the water vapour permeability increased. The difference in the vapour pressure across the film is influenced by the effect of the water activity on the surroundings at both sides of the film that leads to the mass transfer of water vapour from the high vapour pressure to the low vapour pressure surroundings. Since an increase in temperature results in an increase in the WVTR, the water vapour permeability also increases for the same reason. In terms of the barrier, an increase in the water molecule content will result in lower water vapour barrier properties (Cuq et al., 1997).

\section{Conclusion}

The relative humidity and temperature are two imperative factors that affect the water sorption and permeability properties of edible films. Thus in terms of the final applications of edible film made from potato peel waste these factors need to be controlled to ensure the efficiency of the edible film as an alternative food packaging material. To reduce the amount of moisture uptake by the edible films and/or food products packaged with the films and hence increase their shelf life, it is recommended for the films to be kept at a low relative humidity and temperature.

\section{Acknowledgements}

This work was supported by the Science Fund, Ministry of Science, Technology and Innovation Malaysia (Project number 06-01-04-SF1828 and Vote number 5450731).

\section{References}

Akoy, E., Von Horsten, D., \& Ismail, M. (2013). Moisture adsorption characteristics of solar-dried mango slices. International Food Research Journal, 20(2), 883-890. Retrieved from http://www.ifrj. upm.edu.my/20\%20(02)\%202013/52\%20IFRJ\%2020\%20(02)\%20 2013\%20Elamin.pdf.

Alakali, J. S., \& Satimehin, A. A. (2009). Moisture adsorption characteristics of ginger (Zingiberofficinale) powders. Agricultural Engineering International: CIGR Ejournal, 6(1286), 1-19. Retrieved from http:// www.cigrjournal.org/index.php/Ejounral/article/view/1286/1227.

Azeredo, H. M. C., Miranda, K. W. E., Rosa, M. F., Nascimento, D. M., \& Moura, M. R. (2012). Edible films from alginate-acerola puree reinforced with cellulose whiskers. $L W T-$ Food Science and Technology (Campinas.), 46(1), 294-297. http://dx.doi.org/10.1016/j. lwt.2011.09.016.

Bajpai, S. K., Navin, C., \& Ruchi, L. (2011). Water vapor permeation and antimicrobial properties of sago starch based films formed via microwave irradiation. International Food Research Journal, 18, 417-426. Retrieved from http://www.ifrj.upm.edu.my/18\%20 (01)\%202011/(44)\%20IFRJ-2010-148.pdf.

Bergo, P. V. A., Carvalho, R. A., Sobral, P. J. A., Santos, R. M. C., Silva, F. B. R., Prison, J. M., Solorza-Feria, J., \& Habitante, A. M. Q. B. (2008). Physical properties of edible films based on cassava starch as affected by the plasticizer concentration. Packaging Technology and Science, 21(2), 85-89. http://dx.doi.org/10.1002/pts.781.

Bourlieu, C., Guillard, V., Vallès-Pamiès, V., Guilbert, S., \& Gontard, N. (2009). Edible moisture barriers: How to assess of their potential and limits in food products shelf life extension? Critical Reviews in Food Science and Nutrition, 49(5), 474-499. PMid:19399672. http:// dx.doi.org/10.1080/10408390802145724.

Bourtoom, T. (2008). Edible films and coatings: characteristics and properties. International Food Research Journal, 15(3), 237-248. Retrieved from http://www.ifr.upm.edu.my/15\%20(3)\%202008/01.\%20 Bourtoom,\%20T.pdf.

Britto, D., \& Assis, O. B. G. (2010). Hydrophilic and morphological aspects of films based on quaternary salts of chitosan for edible applications. Packaging Technology and Science, 23(2), 111-119. http://dx.doi.org/10.1002/pts.884.

Chowdhury, T., \& Das, M. (2012). Moisture sorption isotherm and isosteric heat of sorption of edible films from blends of starch, amylose and methyl cellulose. International Food Research Journal, 19(4), 16691678. Retrieved from http://www.ifrj.upm.edu.my/19\%20(04)\%20 2012/52\%20IFRJ\%2019\%20(04)\%202012\%20Das\%20(205).pdf.

Chukwu, O. (2010). Moisture-sorption study of dried date fruits. $A U$ Journal of Technology, 13(3), 175-180. Retrieved from http://www. journal.au.edu/au_techno/2010/jan2010/journal133_article07.pdf.

Cuq, B., Gontard, N., Aymard, C., \& Guilbert, S. (1997). Relative humidity and temperature effects on mechanical and water vapor barrier properties of myofibrillar protein-based films. Polymer Gels and Networks, 5(1), 1-15. http://dx.doi.org/10.1016/S09667822(96)00026-3. 
Das, M., \& Chowdhury, T. (2016). Heat sealing property of starch based self-supporting edible films. Food Packaging and Shelf Life, 9, 64-68. http://dx.doi.org/10.1016/j.fpsl.2016.05.002.

Das, M., \& Das, S. K. (2002). Analysis of moisture sorption characteristics of fish protein myosin. International Journal of Food Science \& Technology, 37(2), 1-5. http://dx.doi.org/10.1046/j.1365-2621.2002.00560.x.

Farvin, K. H. S., Grejsen, H. D., \& Jacobsen, C. (2012). Potato peel extract as a natural antioxidant in chilled storage of minced horse mackerel (Trachurus trachurus): Effect on lipid and protein oxidation. Food Chemistry, 131(3), 843-851. http://dx.doi.org/10.1016/j. foodchem.2011.09.056.

Jamieson, P. D., Porter, J. R., \& Wilson, D. R. (1991). A test of computer simulation model ARCWHEAT1 on wheat crops grown in New Zealand. Field Crops Research, 27(4), 337-350. http://dx.doi. org/10.1016/0378-4290(91)90040-3.

Jouki, M., Yazdi, F. T., Mortavazi, S. A., \& Koocheki, A. (2013). Physical, barrier and antioxidant properties of a novel plasticized edible film from quince seed mucilage. International Journal of Biological Macromolecules, 62, 500-507. PMid:24076197. http:// dx.doi.org/10.1016/j.ijbiomac.2013.09.031.

Mali, S., Sakanaka, L. S., Yamashita, F., \& Grossmann, M. V. E. (2005). Water sorption and mechanical properties of cassava starch films and their relation to plasticizing effect. Carbohydrate Polymers, 60(3), 283-289. http://dx.doi.org/10.1016/j.carbpol.2005.01.003.

Mok, C., \& Hettiarachchy, N. S. (1990). Moisture sorption characteristics of ground sun flower nutmeat and its products. Journal of Food Science, 55(3), 786-789. http://dx.doi.org/10.1111/j.1365-2621.1990. tb05231.x.

Mostafa, H., \& Sourell, H. (2009). Equilibrium moisture content of some bioplastic materials for agricultural use (Drip tubes). Agricultural Engineering International: CIGR Ejournal, 6(1180), 1-10. Retrieved from http://cigrjournal.org/index.php/Ejounral/ article/viewFile/1180/1175.

Othman, S. H. (2014). Bio-nanocomposite materials for food packaging applications: types of biopolymer and nano-sized filler. Agriculture and Agricultural Science Procedia, 2, 296-303. http://dx.doi.org/10.1016/j. aaspro.2014.11.042.
Peleg, M. (1998). An empirical model for the description of moisture sorption curves. Journal of Food Science, 53(4), 1216-1219. http:// dx.doi.org/10.1111/j.1365-2621.1988.tb13565.x.

Rizvi, S. S. H. (1986) Thermodynamics of foods in dehydration. In M. A. Rao \& S. S. H. Rizvi (Eds.), Engineering properties of foods (pp. 196-201). New York: Marcel Dekker.

Robertson, G. L. (2012). Food packaging principles and practice. Florida: CRC Press.

Shit, S. C., \& Shah, P. M. (2014). Edible polymers: challenges and opportunities. Journal of Polymers, 2014(427259), 1-13. http:// dx.doi.org/10.1155/2014/427259.

Skurtys, O., Acevedo, C., Pedreschi, F., Enrione, J., Osorio, F., \& Aguilera, J. M. (2010). Food hydrocolloid edible films and coatings. New York: Nova Science Publishers.

Slavutsky, A. M., \& Bertuzzi, M. A. (2016). Improvement of water barrier properties of starch films by lipid nanolamination. Food Packaging and Shelf Life, 7, 41-46. http://dx.doi.org/10.1016/j.fpsl.2016.01.004.

Strauss, U. P., Porcja, R. J., \& Chen, Y. (1991). Volume effects of starch water interactions. In H. Levine \& L. Slade (Eds.), Water Relationships in Foods (pp. 351-363). New York: Plenum Press.

Suppakul, P. (2006). Moisture sorption characteristics of cassava flour film. In Proceedings of the 15th IAPRI World Conference on Packaging, Tokyo, Japan.

Talja, R. A., Helén, H., Roos, Y. H., \& Jouppila, K. (2007). Effect of various polyols and polyol contents on physical and mechanical properties of potato starch based films. Carbohydrate Polymers, 67(3), 288-295. http://dx.doi.org/10.1016/j.carbpol.2006.05.019.

Turhan, M., Sayar, S., \& Gunasekaran, S. (2002). Application of Peleg model to study water absorption in chickpea during soaking. Journal of Food Engineering, 53(2), 153-159. http://dx.doi.org/10.1016/ S0260-8774(01)00152-2.

Weng, W. Y., Tao, Z., Liu, G. M., Su, W. J., Osako, K., Tanaka, M., \& Cao, M. J. (2014). Mechanical, barrier, optical properties and antimicrobial activity of edible films prepared from silver carp surimi incorporated with $\varepsilon$-polylysine. Packaging Technology and Science, 27(1), 37-47. http://dx.doi.org/10.1002/pts.2001. 